\title{
Trascender la superficie: El cuerpo como enunciante retórico e ideológico en el documental Noticias
}

\section{Transcending the Surface: The body as a Rhetorical and Ideological Enunciator in the Documentary Noticias.}

\section{Resumen}

El texto plantea una interpretación crítica acerca de la representación del cuerpo en el documental Noticias (2009) de los directores chilenos Betina Perut e Iván Osnovikoff. Para tal objetivo se hace hincapié en la capacidad que presenta el concepto de cuerpo sin órganos para desestructurar la reflexión intelectual que ha sido universalmente hegemónica a la hora de apreciar una obra de arte. De esta manera, se plantea que el cuerpo en la película analizada, tiene como objetivo la desjerarquización de la mirada en el acto intelectual de apreciar una obra cinematográfica. El cuerpo entendido, entonces, como una organicidad sensible que invierte la reflexión intelecto/cuerpo presenta la capacidad de realizar una crítica a la representación cinematográfica clásica y un cuestionamiento a la configuración social e ideológica en la cual el cine históricamente ha desar rollado su discurso.

Palabras claves cuerpo, representación, desjerarquización, idolología, cuerpo sin órganos, intelecto.

\begin{abstract}
The text raises a critical interpretation about the representation of the body in the documentary Noticias (2009) of the Chilean directors Bettina Perut and Ivan Ossnovikof. To this end, it is emphasize on the capacity of the concept of a body without organs to destroy the intellectual reflection that has been universally hegemonic when it comes to appreciating a work of art. In this way, it is argued that the body in the analyzed film, aims to the dehierarchization of the gaze in the intellectual act of appreciating cinematographic work. The
\end{abstract}


body understood,then, as a sensitive organicity that inverts the reflection of body/intellect, shows the capacity of making a critique of the classic cinematic representation and a questioning to the ideological and social configuration in which, historically, the cinema has developed its discourse.

Keywords body, representation, de-hierarchization, idolology, body without organs, intellect.

\section{Introducción: La irrupción del cuerpo en el cine de Perut+Osnovikoff}

Uno de los temas centrales en el cine de los documentalistas chilenos Betina Perut e Iván Osnovikoff ha sido el cuerpo. En él han situado una de sus principales problemáticas, guiadas especialmente por los cuerpos deshechos, deformados, fatigados o en franca descomposición. Desde su primer largometraje Chi, chi chi, le, le, le Martín Vargas de Chile (1999), podemos apreciar la idea de un cuerpo colapsado, extenuado y desfigurado por el boxeo y el alcoholismo. Quizás este sea el primer gesto crítico que realizan los directores nacionales, ya que su personaje quiebra el canon corporal convencional al cual el cine chileno nos ha tenido acostumbrados, basado en el modelo del starsystem. Proponiendo, en cambio, un sujeto que presenta cierta anomalía corporal y psicológica en sintonía con el ejercicio reflexivo sobre el cuerpo que ha realizado el cine moderno desde los años sesenta, intuimos además, que éste ha sido el cine que ha formado el gusto estético de ambos autores. De una manera muy clara en el libro La Historia del cuerpo se refieren a lo que decimos:

el cine moderno desmoronó el proyecto de domesticación y de encantamiento de los cuerpos cuyos efectos fascinantes funcionaron durante casi treinta años de apariencias (1930-1960) en la historia del cine. Los cuerpos de la pantalla, en un momento determinado, quedaron como desprendidos de su forma benevolente, reexpuestos, asalvajados, violentados, vueltos hacia lo primitivo de sus orígenes cinematográficos. 
Se cuestiona bruscamente cierto encantamiento de las apariencias. (Courtine 369)

Un caso particularmente icónico al respecto ha sido el documental Noche y niebla (1955) del cineasta francés Alain Rasnais, en él podemos apreciar las montañas de cabelleras, de enjutos cadáveres y las cabezas decapitadas amontonadas en canastos, que demuestran el holocausto. El ejercicio crítico que plantea el director, por lo tanto, evidencia el objetivo ideológico de su propuesta, la que hermana el recurso estético con la reflexión histórico-filosófica que plantea este filme: el holocausto no es producido por las intenciones macabras de una mente desquiciada, sino por los efectos de la historia reciente, es decir, como "productos posibles de la razón técnica, de la Modernidad" (Corro, Axiografía). En este sentido, la incorporación de una mirada persistente sobre los cuerpos, no tiene la intención de volver de manera estética hacia los cuerpos primitivos y asalvajados de los orígenes de la cinematografía. Por el contrario, está orientada a establecer la imagen como el enunciante de la explicación ideológica y filosófica que intenta proponer Resnais sobre la historia europea reciente. La imagen cinematográfica, entonces, convierte la visualidad en el contenido epistemológico que comentamos anteriormente.

El gesto crítico que realizan Perut y Osnovikoff en sus películas, por lo tanto, tiene que ver en gran medida con la idea de igualar la imagen a una propuesta ideológica que exceda lo puramente narrativo y que, a su vez, ponga en crisis la representación cinematográfica que ha elaborado la cinematografía. En este sentido, el trabajo de los documentalistas nacionales ha tenido un desarrollo y un interés significativo por el cuerpo como una organicidad capaz de poner en entredicho a la imagen fílmica convencional producto de la representación de corporalidades en manifiesta decadencia. De este modo, podríamos decir que los directores que mencionamos son pioneros en la incorporación plástica y denotativa de cuerpos fustigados en la filmografía chilena. Esta cuestión, si bien bajo un registro diferente y desde un punto de vista más apegado al clasicismo, ha 
sido una tendencia en el cine de la última década, especialmente de películas como Violeta se fue a los cielos de Andrés Wood o Post Mortem de Pablo Larraín. Por lo mismo, Pablo Corro en el libro Retóricas del cine chileno, ensayos con el realismo escribe al respecto que:

uno de los destinos posibles del itinerario hacia la intimidad que sigue el cine chileno hace ya un par de décadas parece ser el de los cuerpos, entre otros, el de ciertos cuerpos monumentales, y no tiene nada de extraño que implique el acceso a esos cuerpos a partir de sus muertes puesto que no hay mejor condición de disponibilidad de ellos que el de la muerte. (227)

Tanto en la película de Larraín como en la de Wood, podemos apreciar cuerpos de ídolos en un estado de fallecimiento. Del mismo modo como ocurre en el filme de Perut+Osnovikoff, La muerte de Pinochet (2011), la mirada tanatólogica y escópica de la cámara nos hace percibir cuestiones que de otro modo no podríamos apreciar. De manera especial, en la película sobre Pinochet, podemos inclinarnos a pensar que la imagen nos está diciendo algo que va más allá que lo puramente narrado, con recurrencia nos sentimos interpelados como espectadores. El visionado de este filme, por lo tanto, nos hace reflexionar sobre su propuesta de una manera diferente a la percepción intelectual que podemos notar cuando observamos otro tipo de películas que muestran cuerpos muertos. Esto se debe a que la operación intelectual que desarrollamos al visionar un filme de los directores chilenos es similar a la lógica de la sensación que observa Gilles Deleuze en la obra de Francis Bacon.

En este sentido una película que, creemos, es fundamental para poder acceder a la propuesta estética deleziana es el filme Noticias (2009). De un modo similar a lo que ocurre en La muerte de Pinochet, podemos observar una imagen que rompe con la representación, es decir, se presenta una imagen no-narrativa. En ella, en consecuencia, ya no existe la intención de unificar un relato en una 
historia de estilo clásico, sino por el contrario una imagen que remueva la sensibilidad del espectador y le haga sentir una experiencia estética en un mismo nivel sensible. En otras palabras, que el cuerpo observado nos haga pensar la experiencia estética como una unidad enunciativa, en un ejercicio parecido a la propuesta ideológico-plástica de Resnais. En este sentido, la mirada persistente sobre cadáveres presenta un recurso que intensifica ideológicamente la plasticidad del cuadro, en una manifiesta reflexión retórica que tiende a unificar el motivo ideológico con la técnica cinematográfica bajo un mismo concepto estético: el cuerpo. Esta situación, por lo tanto, bien puede pensarse desde la lógica de la sensación que propone Deleuze en el libro que dedica a la obra pictórica de Francis Bacon que mencionamos con anterioridad. Desde aquí, entonces, el objetivo de este trabajo será intentar proponer una mirada que vincule el concepto de cuerpo sin órganos que observa Deleuze en las pinturas de Bacon, como una reflexión sobre la obra de arte y el papel que juega el espectador en la concreción de un sistema estético y que, podríamos apreciar en el filme Noticias de los documentalistas Perut+Osnovikoff. En esta película, creemos, predomina el cuerpo como figura central de la propuesta retórica e ideológica que los cineastas problematizan en el filme que mencionamos. La corporalidad, en este sentido, se presentará como una manifestación ideológica que, al tiempo que desarticula la representación cinematográfica convencional, reflexiona acerca de la sociedad que la produce. La desmembración de la organicidad del cuerpo, en este aspecto, tendrá un papel de preponderancia, ya que posibilitará la concreción sensible de un todo estético, es decir, el cuerpo genera la sensación y al mismo tiempo la recibe.

\section{El cuerpo y la crisis de la representación}

El filme Noticias, como hemos mencionado, presenta una inquietante mirada hacia cuatro cadáveres, cuya causa de muerte de los sujetos expuestos son 
las de suicidio, homicidio, accidente y causa natural, o vejez. Asimismo cada presencia en el cuadro cinematográfico está desmembrada por la incorporación de segmentos contingentes. Estos son: la peregrinación masiva a la virgen de Lo Vázquez, personas sufrientes en la posta central, los papiones del zoológico metropolitano y el estado de catástrofe que dejó el volcán Chaitén en la ciudad del mismo nombre. En este sentido, la persistencia con la cual son expuestos los cadáveres en el plano cinematográfico con una escala que va desde el plano general, al primer plano para luego dar paso al plano detalle, hace que una de las entradas posibles a esta película sea la de los cuerpos. El papel que juegan estos en la estructura del argumento es preponderante, ya que, a partir de ellos Perut y Osnovikoff ponen en crisis a la representación cinematográfica clásica ${ }^{1}$. Los cuerpos exhibidos, entonces, desestructuran la narración convencional, ya que ellos son expuestos entre diferentes segmentos que, en apariencia, no presentan una relación narrativa entre un plano y otro. De este modo podemos hacer notar que este sería un primer gesto crítico hacia lo representado, teniendo en consideración lo que plantea Deleuze al respecto de la pintura figurativa, es decir:

la representación implica, en efecto, la relación de una imagen con un objeto que supone ilustrar; pero implica también la relación de una imagen con otras imágenes en un conjunto compuesto que da precisamente a cada una su objeto. La narración es el correlato de la

${ }^{1}$ La representación cinematográfica clásica hace referencia a la industria hollywoodense, que supo desarrollar técnicas narrativas que tendieron a una estandarización en los modelos de representación y que a menudo suele situarse bajo la delimitación realizada por David Borwell, Janet Staiger y Kristin Thompson, entre el periodo que va desde 1917 a 1960. No obstante, comprenderemos que incluso una película contemporánea puede situarse dentro de esa categoría, según su estructura narrativa. Un filme clásico está constituido por una trama y un argumento de fácil acceso, que no representa una problemática estética ni narrativa compleja. Es así, como el teórico David Brodwell se refiere al cine clásico: "El cine de ficción ha conseguido predominar un modo de narración. Tanto si le llamamos cine corriente, como dominante o clásico, intuitivamente reconocemos en ello una película ordinaria de visionado fácilmente comprensible". El cine clásico, tiende a la concepción de un filme bien balanceado y a una trama bien contada sin dejar ningún cabo suelto. Es por ello que su narración está sujeta a lo que se pudiera llamar normal. Dentro del filme clásico, entonces, los modos de narración se ajustan a las normas prestablecidas, a lo que Bordwell llamó el formato de historia canónica basada en la poética de Aristóteles, esto es la exposición, el estado de la cuestión, introducción del protagonista y demás. 
ilustración. Entre dos figuras se desliza siempre una historia, o tiende a deslizarse, para animar el conjunto ilustrado. (Deleuze, Francis 5)

En el caso cinematográfico esta noción general ocurre de un modo similar. La relación entonces se dará entre un plano y otro para realzar un relato que cuente una historia unificada. Ahora bien, ante la anulación de las elipsis, es decir, las junturas que ordenan la narración clásica, podemos apreciar un filme que no presenta una relación entre una imagen y otra o en este caso entre un plano y otro. La figura de los muertos en este sentido, tiene por vocación la de separar las imágenes desestructurando la continuidad lógica entre segmentos contingentes filmados. Por otro lado, los cuerpos mostrados en Noticias presentan un aislamiento respecto de otros objetos en el decorado, es decir, están extrañados de su contexto. Esto hace que en un mismo cuadro se anule la relación entre objeto y figura, el plano detalle además, ahonda en esta idea. Esto sin duda altera la representación cinematográfica desde el punto de vista visual y no narrativo como había sido costumbre en el cine moderno. Esto quiere decir, que el cuerpo en su aislamiento es rareficado, es decir, la imagen presenta muy pocas cosas a su alrededor lo que implica una imagen que tiende a ser legible más que puramente visible. De este modo, "se anula la representación cuando se pone todo el acento sobre un solo objeto" (Deleuze, Imagen 28), en el caso de Noticias el cuerpo y su relación con otros objetos o figuras. Esta cuestión es altamente crítica respecto del cine y presenta un primer punto de cuestionamiento a la imagen tradicional, ya que Deleuze, más adelante agrega que "aislar es entonces el medio más simple, necesario pero no suficiente, para romper con la representación, quebrar la narración, impedir la ilustración, liberar la Figura: mantenerse en el hecho" (Deleuze, Francis 5).

El aislamiento del cuerpo que se da en una pintura de Bacon, por lo tanto, tiene como primer objetivo la desvinculación de este con otras imágenes u objetos dentro de un mismo cuadro que hagan de la pintura un hecho figurativo clásico que presente una narración. Asimismo, los cuerpos separados y fragmentados con 
la cámara en el documental Noticias, tienen como objetivo un cuestionamiento binario a la representación. Mientras por un lado, desarticulan la unión entre imágenes de cada plano segmentado, por otro, rarefican el cuadro donde aparecen los cuerpos, no pudiendo el espectador relacionarlos con otros objetos. Es decir, el cuerpo en Perut y Osnovikoff presenta dos dimensiones: la primera, una desarticulación narrativa por medio de la eliminación de las elipsis en el argumento de la película. Una segunda, estructurada sobre la imagen visual de los cuerpos que hace anómala la representación a través de la segregación y desmembramiento retórico de los cadáveres expuestos, reexpuestos y con gran parte de ellos en el fuera de campo o como menciona Pablo Corro en el texto Axiografía o el espacio ético en el documental - El Caso de Noticias: "privilegiando ángulos desconcertantes, rasantes, yacentes, contrapicados, puede ser interpretada como la escandalosa práctica tanatológica de la fotogenia de la muerte" (Corro, Axiografía).

En este sentido, el cuerpo en Noticias no solo quiebra la representación convencional desde los aspectos visuales y narrativos que comentábamos con anterioridad, sino que también, fustiga, carcome y atormenta los cuerpos que ha construido el modelo del starsystem. Es decir, realiza una crítica ideológica al Modelo de Representación Institucional ${ }^{2}$, ya que hace del discurso cinematográfico un suceso autoconsciente y, además, a la figuración corporal de la cinematografía clásica, a través de la exhibición cercana de la muerte. Para lograr poner en crisis la representación, entonces, el uso de la técnica cinematográfica toma un papel de relevancia, ya que al igual que lo que Deleuze observa en los cuadros de Bacon, la anulación de relaciones con otros objetos está

2 Término acuñado por Noël Burch en el libro Praxis de cine, para referirse a los filmes del periodo clásico de Hollywood. Los cuales dependen de un mismo modelo narrativo y dramático que pone al héroe como centro del drama, estructurando una representación que es equivalente a todos los géneros y temáticas del cine de la época. Los filmes, por lo tanto, no presentan diferencias en sus formas retóricas o narrativas sino más bien solo en sus tramas. En este sentido el MRI, es dependiente tanto de la pintura figurativa y realista del siglo XIX en su aspecto visual, como de la novela romántica en su aspecto narrativo. El quiebre con esta institucionalización de la representación viene a partir de los años sesenta con la aparición del discurso moderno en el cine. 
determinada por el tratamiento del color y la técnica que sus cuadros presentan. Asimismo en el documental Noticias el cuerpo es separado de sus relaciones figurativas a través de los elementos técnicos del cine como el plano detalle o la eliminación de las elipsis entre ellos. Tanto en el caso de Bacon como en el caso del filme, por lo tanto, podemos plantear de una manera cercana a la indagación que realiza Deleuze sobre gesto retórico que hemos comentado que, en ella, se anula la representación clásica figurativa y narrativa de la pintura de tradición de caballete y de la pintura moderna, debido principalmente a que los cuadros de Bacon no son ni figurativos ni abstractos. Esto quiere decir que el ejercicio que plantea Perut y Osnovikoff es similar, debido a que los cuerpos presentes no tienen relación con otros cuerpos los que, a su vez, están mostrados de manera rereficada, es decir la estética de esta película no es abstracta pero tampoco es realista, la mirada constantemente nos hace pensar que está ocurriendo algo más de lo estrictamente narrado, situación producida por la representación anómala que estructuran los cineastas.

Ahora bien, la mayoría de aquellos recursos teóricos están determinados por la lógica de la sensación, es decir que el lenguaje cinematográfico, así como el lenguaje pictórico en Bacon, es un vehículo para indagar en una nueva relación intelectual donde la mirada se invierte. Esto quiere decir que la obra de arte no estará encaminada al cerebro (intelecto), sino que al cuerpo. En este aspecto Deleuze menciona que la obra de arte está "dirigida y presentado por y para el cuerpo" (Deleuze, Francis 30). Para esto el filósofo plantea y reorganiza el concepto de Cuerpo sin órganos acuñado por Artaud, es decir un arte estructurado a través del cuerpo para remover al sujeto y que éste sienta la obra de arte como un todo estético sin necesidad de que tenga una relación de tipo intelectual clásica, basada en el pensar/sentir como la que comentábamos más arriba. La representación anómala en Noticias, entonces, presentará como característica principal seguir el camino trazado por la lógica de la sensación, para así, llevar a cabo la ruptura con el cine convencional y de ese modo realizar la crítica 
ideológica a la realidad expresada en los noticieros, gesto que se estructura por medio de los cuerpos (re)presentados.

\section{El cuerpo sin órganos: sobre la desjerarquización de la mirada}

Uno de los aspectos principales de los que habla Deleuze en la lógica de la sensación tiene que ver con el cuerpo sin órganos. En él ve el paso fundamental que da el cuerpo pintado para intervenir en el cuerpo del espectador y con ello afectarlo sensorialmente. Como primer punto a tener en consideración es que cuando el filósofo francés habla sobre cuerpo sin órganos no está queriendo decir que el cuerpo no tenga órganos, por el contrario, su definición habla de órgano como una organicidad, es decir un orden, por lo tanto, no se trata de un cuerpo que no tenga órganos sino más bien de un cuerpo que niega la organicidad para desestructurar la manera en la cual sentimos, nos afectamos y somos removidos por una obra de arte. El mismo Deleuze escribe que "en efecto, el cuerpo sin órganos no carece de órganos, solamente de organismo, es decir, de esta organización de los órganos" (Deleuze, Francis 29).

La carencia de organismo, entonces, es un elemento que permite desvincular la tradicional manera en la cual percibimos una obra de arte, para así poder sentirla como una unidad que vaya directo al cuerpo y no al cerebro, es decir que nos permita hacer una inversión en el ejercicio intelectual artístico clásico que ha estructurado su explicación en una relación que va desde el cerebro hasta el aparato sensible comúnmente. Deleuze, por el contrario, plantea una deconstrucción en este sentido argumentando que en la lógica de la sensación debe existir una horizontalidad entre cerebro y cuerpo. Es decir, la obra no estaría afectando un único nivel sensorial determinado por el intelecto, sino por el contrario, recorre el cuerpo por completo afectando el sistema nervioso para así remover la sensibilidad del espectador desde una lógica de la sensación, 
cambiando el convencionalismo tradicional pensar/sentir por uno que esté ligado al sentir/pensar. A raíz de lo anterior agrega más adelante que:

el cuerpo sin órganos se define entonces por un órgano indeterminado, en tanto que el organismo se define por los órganos determinados: ¿en lugar de una boca y de un ano que amenazan descomponerse, por qué no tener un único orificio polivalente para la alimentación y la defecación? (Deleuze, Francis 29)

Esto quiere decir que el concepto del cual habla Deleuze, tiene la intención de generar la desjerarquización de los órganos y la sensación, por lo tanto la experiencia estética se transformaría en una cuestión horizontal absoluta. Con ello la sensación de lo visual afectaría al cuerpo por completo como una unidad sensible que ve en el mismo cuerpo-vivo un desacople de las formas tradicionales del sentir. Lo pintado y lo filmado, entonces, es sensación y "la pintura es producida y dirigida desde y hacia el cuerpo" (Deleuze, Francis 26) con el fin de conmoverlo hasta el punto de perturbar el orden de los sentidos y disolver el objeto en el sujeto y al revés.

En este sentido, la representación anómala que se estructura en Noticias, creemos, tiene como intención, que la obra de arte ocurra en el cuerpo del espectador para de ese modo poner de manifiesto la crítica ideológica que ejerce esta producción. Esto quiere decir, que los documentalistas chilenos van al centro del relato noticioso y no al margen emocional como ha ocurrido en los noticieros. Estos últimos, habitualmente han sobredramatizado intensificando el padecimiento de los sujetos mostrados. El acto de mostrar cadáveres, en consecuencia, presenta como objetivo central cuestionar el carácter sobrepedagógico y la narración dramática ideologizada de los noticieros, a fin de remover al espectador en un mismo nivel sensible, es decir, hay una sensación de diferentes órdenes y no diferentes sensaciones. La mirada del cuerpo hacia el cuerpo, por lo tanto, desregula los sentidos y atraviesa los niveles del sentir, ya 
que la sensación opera directamente en el sistema nervioso. De esta forma, el cuerpo sin órganos es un organismo indeterminado y sin relaciones jerárquicas. Esto hace, que las sensaciones operen en un todo y no sobre órganos que subordinen sensitivamente a otros de una manera determinada y parcelada como ocurre en la representación clásica que, por su disposición narrativa, está dirigida solamente al intelecto. En este sentido, aquel proceso plantea cómo el órgano indeterminado al ojo, pero no en la versión tradicional que ve a éste nada más que como un órgano perceptor para hacer llegar una imagen al cerebro, sino que esta vez, como un órgano indeterminado que tiene la capacidad de hacernos sentir la figura (el cuerpo) como pura presencia, es decir, la corporalidad exhibida nos instala ojos en todas partes para así poder sentir una sola sensación de diferentes órdenes. Es por lo mismo, que el cuerpo en Noticias opera como una manera de desarticular el modo en la cual percibimos los noticieros, haciéndonos sentir en forma viva cuasi-carnal el padecimiento y el sufrimiento de los cadáveres en nuestro propio cuerpo:

la mirada de Perut y Osnovikoff se reconoce en la práctica del distanciamiento, pero no con la intención epistemológica de descubrir causalidades, sino en el sentido de restituir la vitalidad a los fenómenos, examinando su virtualidad morfológica que, hay que aceptar, contiene la del anonadamiento, la de la disformidad. (Corro, Axiografía)

Esta misma disformidad, nos hace sentir lo mostrado de una manera cercana y más bien clínica en Noticias, como una desjerarquización en la experiencia estética clásica y en la manera en la cual comprendemos la imagen visual tradicional ligada a la reflexión pensar/sentir. Es decir, no hay prejuicios o conceptualizaciones anteriores que intervengan en nuestra sensación y en la manera en la cual entendemos una obra, ya que la lógica del sentido se invierte y la figura es la forma sensible que actúa directamente sobre el sistema nervioso y provoca el pensamiento, luego de haber sentido y no antes. Vale decir, la obra 
artística podría ser pensada como una condición autónoma, en cuanto el sentido está en ella y en la manera en que somos afectados y nos dejamos afectar, más que en el que la intelectualizamos. De esta manera, en una de las escenas podemos observar cuerpos sufrientes esperando el turno de ser atendidos en la posta central, podemos ser removidos y sentir el dolor que aqueja a aquellos sujetos, sin embargo no de una manera en la cual sintamos compasión o empatía por su dolor, sino más bien, porque el dolor mismo, en cuanto sensación, se ha apoderado de nuestra subjetividad, debido principalmente a que, la imagen que presenta Noticias, mediante la persistente mirada clínica de los cuerpos hace que nos miremos en ellos fundiéndonos en el interior del cuadro cinematográfico. En este sentido, la mirada tanatólogica, genera un desacople en el cuerpo del espectador, interpelándolo hasta el punto de incomodarlo de tal manera que sienta el desgarro de los cuerpos expuestos. El afamado teórico de cine español Ángel Quintana se refiere al cine moderno y su carácter de provocar sensaciones planteando que "las palabras son incapaces de determinar el dolor, este sólo puede expresarse a partir de los silencios" (Quintana 116).

De ahí que al mismo tiempo, los cuerpos exhibidos en Noticias, no presenten musicalización que intensifique las sensaciones o una voz en off que elabore un discurso que explique o que describe el contexto del asunto, que narre el proceso, en Noticias, en cambio, sólo hay silencio, ya que el dolor debemos experimentarlo como espectadores para poder lograr una experiencia estética parecida a la que observa Deleuze en la obra de Francis Bacon guiada por las sensaciones.

\section{Conclusión: La reflexión ideológica en Noticias}

Las imágenes a las que recurren Perut+Osnovikoff en Noticias, constantemente están relacionadas con lo obsceno: el cadáver, el sufrimiento, la descomposición o el padecimiento del cuerpo. En este sentido, lo que no se puede 
ver en las noticias se ve en el documental, que no son otra cosa que efectos impresentables de trastienda noticiosa: las manipulaciones del cadáver, los procedimientos forenses del hecho policial, las pistas que aporta la intimidad de la víctima o las anotaciones en el diario de vida de la suicida. Gracias a ello, en consecuencia, la reflexión ideológica que podemos observar en este documental tiene que ver profundamente con la alteración de la mirada que se puede experimentar en tres niveles distintos. Uno de ellos guarda relación con la inversión de la mirada a lo narrado y representado por los noticieros televisivos, realizando de este modo, un cuestionamiento a la estructura dramática que realizan los telediarios. Otro es la reflexión ideológica sobre el cine como discurso autoconsciente que se comprende a sí mismo y reflexiona sobre sus propias problemáticas de representación. Y una última que se manifiesta en las dos anteriores y es la que nos parece más relevante, ya que aglutina esta reflexión ideológica sobre la propia cinematografía bajo el concepto visual y teórico del cuerpo. En este sentido, el cadáver y las corporalidades fustigadas son la forma mediante la cual los documentalistas chilenos realizan la crítica ideológica que hemos mencionado. Es decir, a través de una exhibición de mirada persistente sobre el cuerpo logran invertir el modo en el cual observamos una película y somos parte de ella al mismo tiempo. La sensación, como mencionamos, ya no estará bajo el efecto de la mera relación intelectual sino que ella nos afectará para, de esta manera, sentir realmente la obra de arte y también nuestro cuerpo.

De este modo, las manifestaciones que vemos en este filme, no presentan una explicación aparente y con recurrencia cambian de un plano a otro eliminando las elipsis. Estas acciones sin causas supuestas estarían determinadas por lo contiguo y, en ambos casos, por lo que rodea y es adyacente a los noticieros de televisión y que no puede ser mostrado por los telediarios. Es así como si en los informativos los muertos y enfermos aparecen de manera breve, difusa y distante, en Noticias son mostrados por largo tiempo, en forma detallada y persistente.

En este sentido, el cuerpo sin órganos que presenta el documental, es lo que demuestra la crisis de los acontecimientos, de las acciones y de la 
representación. Es decir, se invierte la mirada, mientras los noticieros prestan atención al drama central y a los protagonistas institucionales. Perut+Osnovikoff privilegian, por el contrario, al cuerpo o al protagonista central de la historia que no es mostrado por la televisión: el cadáver, el sufriente. Así, su mirada opera sobre el margen, pero al mismo tiempo sobre la figura central de su propuesta: el organismo. Esta figura desarticula la manera en la que comprendemos lo visual y desjerarquiza los niveles sensibles del cuerpo interpelando e incomodando al espectador. En este sentido, este gesto bien podría ser entendido bajo el apelativo que el escritor italiano Alberto Moravia observa en el cine de Antonioni cuando menciona que, "pasamos la mayor parte del tiempo arrancando pedazos de yeso de las paredes, es decir, contemplando la realidad sin penetrar en ella ni comprenderla" (Font 149).

En el visionado de Noticias, por lo tanto, no estaríamos contemplando la representación de la realidad que se observa en los telediarios, sino por el contrario, a través de la desjerarquización de los sentidos y de la operación intelectual habitual (pensar/sentir), estaríamos siendo removidos a tal nivel sensible que bien podemos experimentar las sensaciones de una manera completa y unificada pero en diferentes órdenes sensibles. De allí, entonces, que el cuerpo sea el tema central de esta película, ya que busca influir en las sensaciones del espectador estetizando el horror corporal. De este modo, los cuerpos sin órganos y en descomposición que podemos apreciar en Noticias tendrían la función de invertir la mirada sobre el campo estético propuesto. Es decir, en el cuerpo desaparecen los órganos y son remplazados por umbrales o niveles que sienten la obra de arte.

Estos niveles del sentir que hacen del cuerpo un organismo indeterminado, creemos, en Noticias y en la pintura de Bacon representan un gesto ideológico de suma importancia, porque en ellos y, siguiendo a Deleuze, se lograría apreciar la modificación completa de la manera en la que apreciamos una obra de arte, el modo en la que nos afecta y en la forma en la que el artista la constituye. En otras palabras, lo ideológico del concepto cuerpo sin órganos no sería otra cosa que 
una nueva manera de comprender la visualidad, donde el espectador juega un papel preponderante. En este sentido, este último (el espectador) ya no es un receptor sino que el encargado de hacerse afectar y de ser afectado por los cuerpos fustigados que aparecen en estas obras; para que de esta manera, deje el carácter de distanciamiento frente a lo (re)presentado, donde el problema del sentido ya esté totalmente resuelto. Por el contrario, lo que se busca es una relación horizontal, donde el sentido es propuesto por la obra, por el espectador y por el autor, el que a su vez, desjerarquiza esta problemática. De esta manera, entonces, el sujeto y el objeto son fundidos en una misma experiencia estética dominada por el cuerpo y dirigida hacia él. Noticias, en este contexto logra quebrar el canon convencional sobre la manera como podemos apreciar un documental realizando una reflexión crítica que hermana lo ideológico con lo técnico y el sentido con lo estético, ya que convierte al cuerpo en el enunciante ideológico y plástico de su propuesta crítica.

\section{Bibliografía}

Corro, Pablo. "Axiografía o el espacio ético en el documental - El Caso de Noticias". perutosnovikoff.com. 2009. http://perutosnovikoff.com/2013/09/24/axiografia/. 11 de octubre de 2017 . Retoricas del cine chileno. Ensayos con el realismo. Santiago: Editorial Cuarto Propio, 2012

Courtine, Jean-Jacques. La historia del cuerpo III. El siglo XX, las mutaciones de la mirada. España: Tauros-Historia, 2006

Deleuze, Gilles. Francis Bacon. La lógica de la sensación. México: Editions de la différence, 1984. blogs.fad.unam. Web. 10 oct. 2017 . La imagen movimiento, estudios sobre cine 1. Buenos aires: Ediciones Paidós, 2009

Font, Domènec. Michelangelo Antonioni. Madrid: Editorial Cátedra, 2003 
CATEDRAL TOMADA: Revista de crítica literaria latinoamericana / Journal of Latin American Literary Criticism Trascender la superficie: El cuerpo como enunciante retórico e ideológico en el documental Noticias

Quintana, Ángel. El cine italiano, 1942-1961 del neorrealismo a la modernidad. Barcelona: Ediciones Paidós, 1997. 